OAK RIDGE

NATIONAL LABORATORY

MANAGED BY UT-BATTELLE

FOR THE DEPARTMENT OF ENERGY

\title{
Current and Proposed Process Monitoring at Uranium Conversion Facilities
}

\author{
July 2013
}

Lisa Loden

Kimberly Gilligan

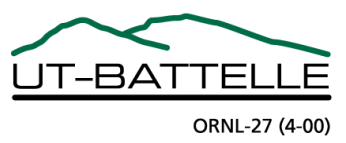




\section{DOCUMENT AVAILABILITY}

Reports produced after January 1, 1996, are generally available free via the U.S. Department of Energy (DOE) Information Bridge.

Web site http://www.osti.gov/bridge

Reports produced before January 1, 1996, may be purchased by members of the public from the following source.

National Technical Information Service

5285 Port Royal Road

Springfield, VA 22161

Telephone 703-605-6000 (1-800-553-6847)

TDD 703-487-4639

Fax 703-605-6900

E-mail info@ntis.gov

Web site http://www.ntis.gov/support/ordernowabout.htm

Reports are available to DOE employees, DOE contractors, Energy Technology Data Exchange (ETDE) representatives, and International Nuclear Information System (INIS) representatives from the following source.

Office of Scientific and Technical Information

P.O. Box 62

Oak Ridge, TN 37831

Telephone 865-576-8401

Fax 865-576-5728

E-mail reports@osti.gov

Web site http://www.osti.gov/contact.html

This report was prepared as an account of work sponsored by an agency of the United States Government. Neither the United States Government nor any agency thereof, nor any of their employees, makes any warranty, express or implied, or assumes any legal liability or responsibility for the accuracy, completeness, or usefulness of any information, apparatus, product, or process disclosed, or represents that its use would not infringe privately owned rights. Reference herein to any specific commercial product, process, or service by trade name, trademark, manufacturer, or otherwise, does not necessarily constitute or imply its endorsement, recommendation, or favoring by the United States Government or any agency thereof. The views and opinions of authors expressed herein do not necessarily state or reflect those of the United States Government or any agency thereof. 


\title{
CURRENT AND PROPOSED PROCESS MONITORING AT URANIUM CONVERSION FACILITIES
}

\author{
Lisa Loden \\ Kimberly Gilligan
}

Date Published: July 2013

\author{
Prepared by \\ OAK RIDGE NATIONAL LABORATORY \\ Oak Ridge, Tennessee 37831-6283 \\ managed by \\ UT-BATTELLE, LLC \\ for the \\ U.S. DEPARTMENT OF ENERGY \\ under contract DE-AC05-00OR22725
}





\section{CONTENTS}

Page

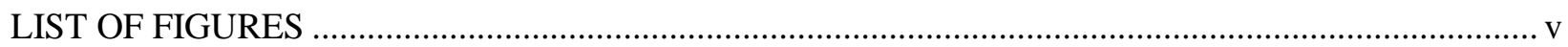

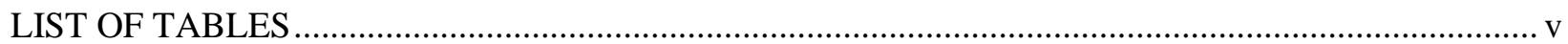

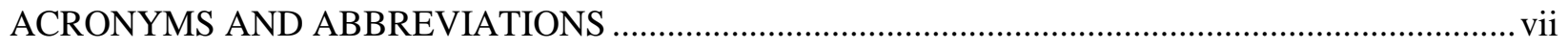

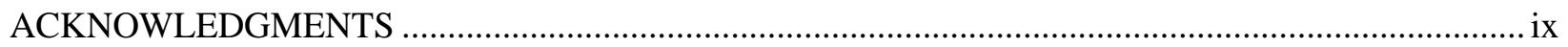

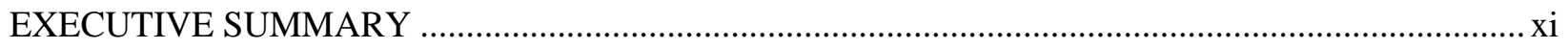

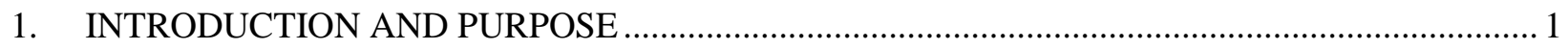

2. CURRENT NUCF SAFEGUARDS REQUIREMENTS AND PROCESS-MONITORING

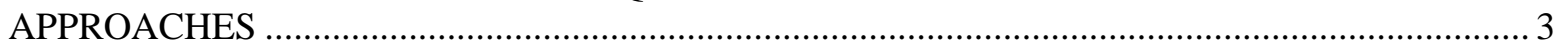

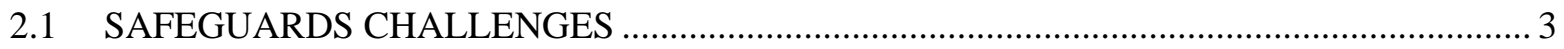

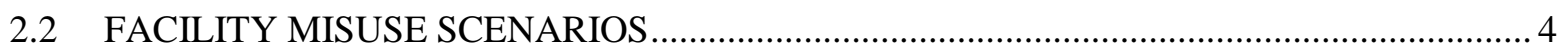

2.3 PROCESS-CONTROL MEASUREMENTS AND METHODS USED AT NUCFS ............... 5

3. CURRENT PROCESS-MONITORING EQUIPMENT USED BY IAEA ….................................. 9

4. NONTRADITIONAL MONITORING METHODS ................................................................... 11

5. PROCESS-MONITORING USE FOR an ENHANCED IAEA APPROACH TO NUCF

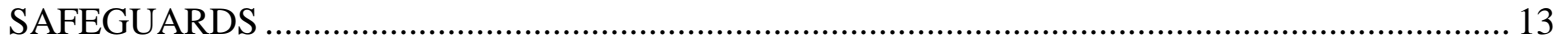

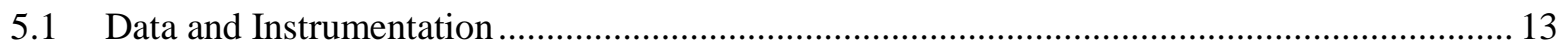

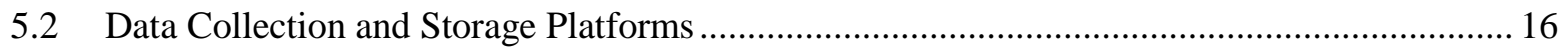

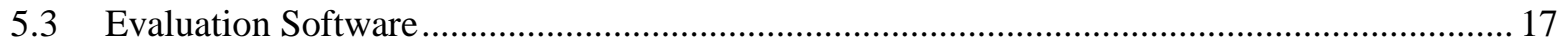

6. COST AND RELIABILITY CONSIDERATIONS …............................................................. 19

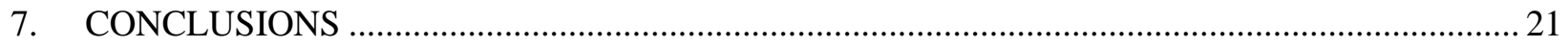

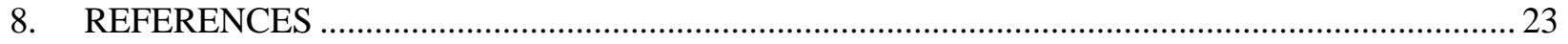





\section{LIST OF FIGURES}

Figure $\quad$ Page

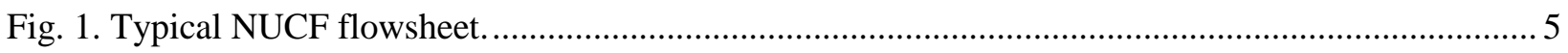

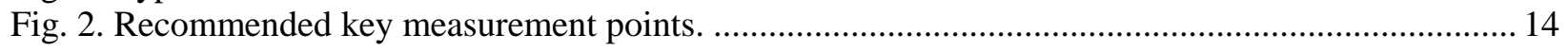

\section{LIST OF TABLES}

Table

Page

Table 1. Process monitoring at NUCFs .7

Table 2. Safeguards process monitoring for the suggested monitoring points at NUCF 



\section{ACRONYMS AND ABBREVIATIONS}

$\begin{array}{ll}\text { ATPM } & \text { advanced thermohydraulic power monitor } \\ \text { AUC } & \text { ammonium uranyl carbonate } \\ \text { DC\&E } & \text { data collection and evaluation } \\ \text { DCS } & \text { distributed control system } \\ \text { DPV } & \text { differential pulse voltammetry } \\ \text { EDAS } & \text { Enhanced Data Authentication System } \\ \text { IAEA } & \text { International Atomic Energy Agency } \\ \text { KMP } & \text { key measurement point } \\ \text { MUF } & \text { material unaccounted for } \\ \text { NH } & \text { ammonia } \\ \text { NOx } & \text { nitrous oxide } \\ \text { NUCF } & \text { natural uranium conversion facility } \\ \text { PLC } & \text { programmable logic controller } \\ \text { SMS } & \text { Solution Monitoring Software } \\ \text { SMMS } & \text { solution measurement and monitoring system } \\ \mathrm{SQ} & \text { significant quantity } \\ \text { TRP } & \text { Tokai Reprocessing Plant } \\ \mathrm{U} & \text { uranium } \\ \mathrm{UF}_{4} & \text { uranium tetrafluoride } \\ \mathrm{UF}_{6} & \text { uranium hexafluoride } \\ \mathrm{UOC} & \text { uranium ore concentrate } \\ \mathrm{UO}_{2} & \text { uranium dioxide } \\ \mathrm{UO}_{3} & \text { uranium trioxide } \\ \mathrm{UO}_{4} & \text { uranyl peroxide } \\ \mathrm{U}_{3} \mathrm{O}_{8} & \text { triuranium octaoxide } \\ \mathrm{wt}_{\%} & \text { percent by weight } \\ & \end{array}$





\section{ACKNOWLEDGMENTS}

The authors thank the US Department of Energy's National Nuclear Security Administration Office of Nonproliferation and International Security (NA-24) the Next Generation Safeguards Initiative for the support given to this project. In particular, encouragement and approval by Dunbar Lockwood and Karyn Durbin of NA-24 are greatly appreciated. 



\section{EXECUTIVE SUMMARY}

This report evaluates the potential use of process monitoring for international nuclear safeguards at natural uranium conversion facilities (NUCFs). International Atomic Energy Agency (IAEA) Policy Paper 18 reinterpreted the starting point of safeguards from the point at which material is at composition and purity suitable for fuel fabrication to the first practical point upstream in the process. This change in the approach for implementing nuclear safeguards resulted in essentially going from item inventories (i.e., cylinders of purified $\mathrm{UF}_{6}$ ) to performing inventories of bulk handling facilities, which can be much more difficult to accomplish.

Process monitoring has long been used to evaluate industrial processes and operating conditions in nuclear and nonnuclear facilities. This report includes a discussion of the types of process monitoring used by operators at NUCFs. Examples of process monitoring practices in NUCFs include monitoring feed, reagent, and product flow rates as well monitoring weighing systems at various points in the process. In this report, examples of process monitoring currently being utilized in IAEA safeguards implementation at other facility types are discussed. Specific examples are offered based on IAEA efforts at the Tokai Reprocessing Plant. It is possible to implement nontraditional monitoring methods in addition to the process monitoring traditionally used at NUCFs. Potential options are the use of in-line analyzers in off-gas streams at various process points or electrochemical methods, such as differential pulse voltammetry.

To better illustrate how process monitoring can enhance safeguards, the report includes a description of probable facility-misuse scenarios for uranium at NUCFs and the identification of key measuring points within NUCFs where process monitoring could be applied for more effective and efficient safeguards. The eight recommended key measurement points discussed at length are

1. uranium ore concentrate (UOC) receipt,

2. UOC feed to dissolver,

3. impure uranyl nitrate storage,

4 \& 5. purified uranyl nitrate and organic streams from extraction,

6. purified and concentrated uranyl nitrate,

7. precipitate product, and

8. $\mathrm{UF}_{6}$ product.

The costs and benefits are summarized before the conclusion is drawn that the integration of process monitoring into a plant's overall safeguards approach could significantly aid the IAEA inspectors in effectively and efficiently verifying state declarations and/or in identifying possible diversions of material. 



\section{INTRODUCTION AND PURPOSE}

This report evaluates the potential use of process monitoring for international nuclear safeguards at natural uranium conversion facilities (NUCFs). The application of safeguards at NUCFs can be quite challenging, given the complexity of these types of facilities. Process monitoring can provide key information during a wide variety of operating conditions that may aid the International Atomic Energy Agency (IAEA) inspectors in their verification of state declarations or in identification of possible diversions of material. The use of process monitoring could minimize the impact on operations and could reduce IAEA staffing requirements for on-site monitoring.

This report draws upon existing documentation to describe the current safeguards requirements for NUCFs and identifies safeguards challenges associated with the current approach. The following are included in this report:

- a summary of the most probable facility misuse scenarios for uranium at NUCFs and an assessment of the IAEA's ability to detect these scenarios,

- a description of the current process control measurements and methods used by the operators at NUCFs,

- a description of process-monitoring equipment currently used by/available to the IAEA at any bulk nuclear material facilities that may have application at NUCFs,

- a description of nontraditional monitoring methods that may provide increased confidence to the IAEA, and

- identification of operator measurements or industrial process-monitoring techniques that might be useful for a more robust IAEA approach. 



\section{CURRENT NUCF SAFEGUARDS REQUIREMENTS AND PROCESS-MONITORING APPROACHES}

The IAEA inspection goal for an NUCF consists of both quantity and timeliness components. These components are regarded as fully attained if all the safeguards criteria relevant to the material types and material categories present at an NUCF have been satisfied and if all anomalies involving one significant quantity (SQ) or more of nuclear material have been resolved in a timely manner. ${ }^{1}$ The two principal safeguards concerns at an NUCF are

- diversion of pure materials (intermediate and final products) for further processing or use elsewhere and

- $\quad$ processing of undeclared feed to produce in a safeguarded facility undeclared pure products (e.g., uranium metal, $\mathrm{UO}_{2}, \mathrm{UF}_{6}$ ) outside safeguards.

The goal of IAEA safeguards is the timely detection of a diversion of an SQ of nuclear material. By IAEA definition, an SQ of natural uranium is 10 MTU with the timeliness being one year using a detection probability of $50 \%$. For small-scale (i.e., 100 tonnes annual production) NUCFs, the IAEA trigger limit of $10 \mathrm{MTU}$ annually would be $10 \mathrm{wt} \%$ of the annual production capacities. A diversion of $10 \mathrm{wt} \%$ uranium throughput of a small-scale plant is significant. Safeguards that encompass feed-and-withdrawal accountability with one or two in-line process monitors should be adequate to detect diversion in smallscale NUCFs. As the production throughput increases, additional process monitoring would improve the ability to detect diversion of material and would meet the detection probability of 50\%. Detecting diversion would be very difficult at very large NUCFs (i.e., 10,000 MTU or greater annual throughput), but by using process monitoring at various key points in the facility, the ability to meet the IAEA detection goals should be achievable.

\subsection{SAFEGUARDS CHALLENGES}

Traditionally, the plant operator makes an accountancy declaration of the material balance for an NUCF, and the IAEA verifies the declaration. The verification measures include the verification of plant design information, auditing of records and reports, and independent measurement of a portion of the nuclear materials that constitute the flows and inventories of the declared material balance.

Until 2003, the point where IAEA material safeguards were first applied at NUCFs was at the very end of the process - the purified $\mathrm{UF}_{6}$. Policy Paper 18 (PP18) reinterpreted paragraph 34(c) of the Comprehensive Safeguards Agreement [INFCIRC/153 (corrected)] to include intermediate conversion plant products such as $\mathrm{UF}_{4}, \mathrm{UO}_{3}, \mathrm{UO}_{2}$, and other compounds with the requisite purity. ${ }^{2}$ It may not be practical or cost-effective to apply safeguards at the first point where the composition and purity requirements of INFCIRC/153.34(c) have been met. According to PP18, verification will be applied at the first practical point upstream in the process (PP18 para. 9). This change in the approach for implementing nuclear safeguards resulted in essentially going from performing item inventories (i.e., cylinders of purified $\mathrm{UF}_{6}$ ) to performing inventories of bulk handling facilities, which can be much more difficult to accomplish.

NUCFs are quite complex chemical-processing facilities that can present a challenge in achieving the IAEA goals for nuclear safeguards. NUCFs typically contain large numbers of process vessels and process pipes that carry not only uranium materials but also supporting process chemicals, water, and gases. Establishing material accountancy in such facilities can be quite difficult. Implementation of material safeguards throughout an NUCF is contingent upon having accurate material accountancy, which 
is predicated on having a thorough understanding of material flow and processing, in-process equipment holdup and material-unaccounted-for (MUF) values. Determination of MUF is not a trivial matter and requires, for example, an in-depth knowledge of facility layout, operational efficiencies, accurate determination of uranium content in nonhomogeneous materials (i.e., waste streams), and an understanding of sample analysis accuracies.

Another challenge for safeguarding an NUCF is the ability to detect whether undeclared feed has been used to produce undeclared product. Detecting this excess production is especially problematic for NUCFs because the feed material is not subject to safeguards on the consignor end. The use of process monitoring could be beneficial in detecting such activities.

\subsection{FACILITY MISUSE SCENARIOS}

Types of diversion must be understood before an adequate strategy can be applied to meet safeguards objectives of (1) detecting the processing of undeclared feed and (2) verifying that declared feed is not being diverted. Different categories of diversion can be elaborated as follows: ${ }^{3}$

- Material substitution: Substitution of feed materials with higher-than-declared uranium content. The uranium concentration is either understated in the product/feed streams or overstated in the waste stream. In either case, the declared uranium throughput quantity is understated in accounting procedures. The substitution of dummy product materials with similar characteristics but no uranium content is also consistent with such activities.

- Equipment alteration: Operating procedures and/or equipment configurations are modified to alter the physical uranium output quantity through diversion earlier in the process or through unreported activities. This can be accomplished by the installation of valves or bypasses to siphon material from the process streams or by the modification or misoperation of equipment to divert uranium to waste streams. Recovery of the material from waste streams would require additional processing to recover the uranium from that source.

- Falsification of records and/or data tampering: Material balance records are adjusted, such as understating throughput, or incorrectly recorded to mask diversion activities.

Detection of material diversion can be difficult in NUCFs, given that nuclear material is being converted, transferred, and recycled in a variety of somewhat complex chemical operations. Each of the operations involves multiple connections; each connection presents an opportunity for diversion. The generation of nonhomogeneous materials in large volumes and sometimes low concentrations also presents a challenge in determining uranium content in various process and waste streams found in an NUCF.

The ability for the IAEA to detect diversion is contingent upon having an accurate accounting of nuclear materials and a thorough understanding of the NUCF equipment configuration and operations. Process material recycle, various types of waste streams, and material holdup in NUCFs make material tracking and accountability difficult. Issues/complications in determining nuclear material inventory/accountability include

- a lack of transparency regarding where nuclear material actually is in the plant (i.e., holdup material in locations that are inaccessible for measurement such as ducts, pumps, pipes, separations areas such as pulsed columns);

- sampling issues such as chemical composition data only being available from samples taken infrequently at a relatively small number of locations;

- poorly estimated measurement error variances; 
- a limited understanding of systematic measurement errors (e.g., results on physical analytical standards are not representative of results on facility material for some flow streams, especially for waste streams); and

- a lack of timely measurement results.

\subsection{PROCESS-CONTROL MEASUREMENTS AND METHODS USED AT NUCFS}

The feed to an NUCF is normally uranium ore concentrate (UOC), which is also referred to as "yellowcake." This feed material can be various compounds of uranium (e.g., sodium diuranate, ammonium diuranate, ammonium uranyl tricarbonate, uranyl peroxide, uranium trioxide), depending upon the mill supplying the feedstock. Regardless of the type of feedstock, a typical NUCF processing operation (see Fig. 1) involves dissolution, purification, and evaporation followed by several chemical conversion steps to produce the desired final product, such as $\mathrm{UO}_{2}$ or $\mathrm{UF}_{6}$.

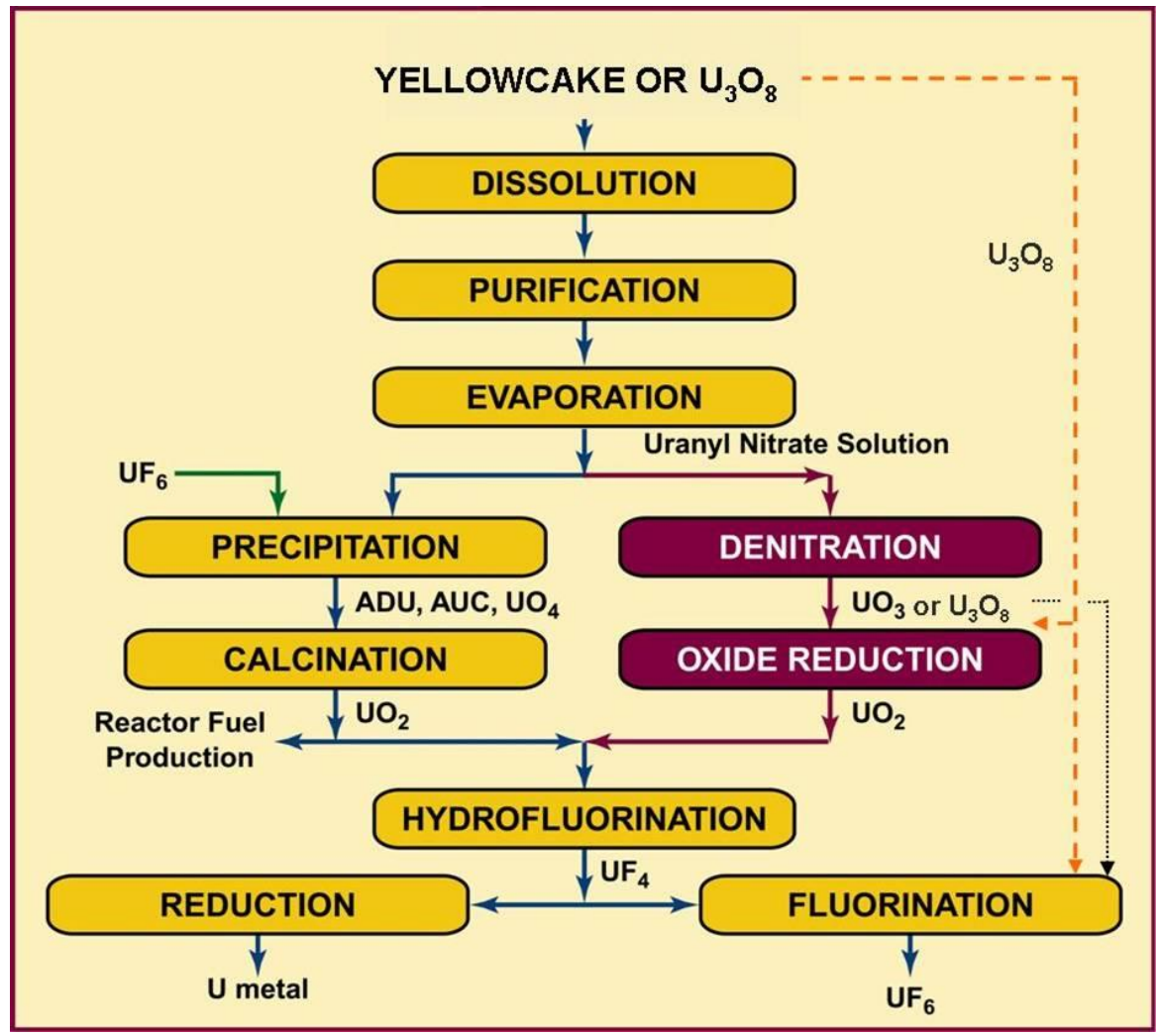

Fig. 1. Typical NUCF flowsheet.

The processes depicted in Fig. 1 can consist of continuous, batch, and semibatch operations. Nearly all processes are continuous at large NUCFs. Smaller plants utilize batch processes. Material may also be stored in tanks or even canned or drummed between processes. In continuous operations, for example, after solvent extraction and the concentration and evaporation steps, the product streams are typically collected in batch collection vessels, which provide interim storage between the various chemical processes. Semibatch operations may include, for example, dissolution, precipitation, oxidation and fluorination processes. Reduction operations are batch operations. 
Process monitoring consists of utilizing process-control measurements to monitor and control plant operations and to detect off-normal conditions. These measurements are used to control the chemical and/or physical processes:

- Examples of process control measurements include

- determination of feed, reagent, and product flow rates;

- concentration/density measurements;

- monitoring of process operating conditions, including temperature, $\mathrm{pH}$, conductivity, pressure; and

- mass measurements using on-line scales.

- Other indicators that may be used for process monitoring in NUCFs include

- valve positions;

- rotational speeds for equipment such as solids feeders or rotary kilns;

- level indication of materials in process equipment and collection vessels; and

— equipment status (e.g., heat tracing, pumps, fans).

Weighing systems may include platform scales, load cells, weigh hoppers, and other devices. Gravimetric feeding systems generally use a volumetric feeder associated with a weighing system to control the discharge of powder from a storage hopper at a constant weight per unit time.

Process control of NUCFs can range from basically all manual operations to those that are fully automatic and remotely controlled by computer. Automated operations use both programmable logic controllers (PLCs) and/or distributed control systems (DCSs). The PLCs and DCSs are connected to sensors and actuators and are used to maintain and control operations in the NUCF and to monitor plant conditions. Feedback control is used to constantly monitor the operating conditions and to adjust equipment to maintain optimum operating parameters. Data trending is possible with these types of control systems and is used by facility operators both for monitoring operating conditions and for process diagnostics and troubleshooting.

Facility operators also perform process sampling of material throughout the NUCF to assess operating conditions in the various chemical processes. This sampling may be performed periodically or continuously using in-line sampling. Examples of in-line analysis that may be found in an NUCF include determination of solution density, conductivity, or $\mathrm{pH}$. In other cases, the operator will remove samples from key measuring points in an NUCF to determine uranium content and will adjust processing based upon the results of the samples. Table 1 provides the types of NUCF process parameters that are typically monitored by an operator along with the types of measurements likely to be utilized for each of these parameters. ${ }^{4}$ 
Table 1. Process monitoring at NUCFs

\begin{tabular}{lll}
\hline \multicolumn{1}{c}{ Process } & \multicolumn{1}{c}{ Process parameters } & \multicolumn{1}{c}{ Measurements } \\
\hline UOC & $\begin{array}{l}\text { Uranium oxide concentrate (UOC) feed } \\
\text { U content }\end{array}$ & \multicolumn{1}{c}{$\begin{array}{l}\text { Dissolution } \\
\text { Accounting with manual samples } \\
\text { taken for destructive analysis }\end{array}$} \\
Dissolver feed & Solids feed rate & $\begin{array}{l}\text { Solids flow rate and/or mass weight } \\
\text { change in feed hopper }\end{array}$ \\
Dissolver & $\begin{array}{l}\text { U concentration in the solution, } \\
\text { free nitric acid in the solution, } \\
\text { temperature }\end{array}$ & $\begin{array}{l}\text { Periodic sampling for solution } \\
\text { density determination, in-line } \\
\text { analysis of pH and temperature; } \\
\text { solution flow rates }\end{array}$ \\
Dissolver product storage & $\begin{array}{l}\text { U concentration in the solution } \\
\text { free nitric acid in the solution }\end{array}$ & $\begin{array}{l}\text { Periodic process sampling for } \\
\text { solution density determination and } \\
\text { U content, in-line pH analysis; tank } \\
\text { level indication }\end{array}$ \\
& & $\begin{array}{l}\text { Collected solids weight; destructive } \\
\text { analysis samples to determine U } \\
\text { content }\end{array}$
\end{tabular}

Solvent extraction
Feed adjust $\begin{aligned} & \text { U concentration in the solution, } \\ & \text { free nitric acid in the solution }\end{aligned}$

Solvent extraction feed/raffinate

Extraction

Extraction product storage

\begin{tabular}{ll} 
Evaporator & \multicolumn{1}{c}{$\begin{array}{c}\text { Evaporation } \\
\text { Solution feed rate; temperatures; } \\
\text { product density }\end{array}$}
\end{tabular}

Product storage

U concentration in the solution
Flow rates, $\mathrm{U}$ concentration in raffinate

Temperatures of aqueous and solvent streams; density of product; free acid content in solvent; liquid flows; U content in product, solvent, and raffinate

$\mathrm{U}$ concentration in the solution
Periodic process sampling for $\mathrm{U}$ content, solution density determination, and acid content; tank level indication

Periodic sampling for $\mathrm{U}$ content in raffinate, in-line flowmeters

Periodic process sampling for $\mathrm{U}$ and acid content in solvent and aqueous streams; solution and organic flow rates; on-line temperature and density measurements; tank level indication (if tanks are used between extraction columns)

Periodic process sampling for $\mathrm{U}$ content; tank level indication

\footnotetext{
Solution flowmeters; in-line density and temperature meters; operating pressures; steam flow rates

Periodic process sampling for $\mathrm{U}$ content; tank level indication
} 
Table 1. Process monitoring at NUCFs (continued)

\begin{tabular}{|c|c|c|}
\hline Process & Process parameters & Measurements \\
\hline \multicolumn{3}{|c|}{ Denitration/precipitation } \\
\hline Reaction vessel & $\begin{array}{l}\text { Solution and reagent gas feed rates; } \\
\text { vessel temperatures; product } \\
\text { density }\end{array}$ & $\begin{array}{l}\text { Solution and gas flowmeters; on- } \\
\text { line temperature meters }\end{array}$ \\
\hline Product collection & $\begin{array}{l}\text { U concentration in the solids; solids } \\
\text { weight }\end{array}$ & $\begin{array}{l}\text { Periodic process sampling for } \mathrm{U} \\
\text { content; on-line weighing at solids } \\
\text { collection point; }\end{array}$ \\
\hline Filtrate/off-gas streams & U concentration & $\begin{array}{l}\text { Periodic process sampling for } \mathrm{U} \\
\text { content }\end{array}$ \\
\hline \multicolumn{3}{|c|}{ Oxidation } \\
\hline Reaction vessel & $\begin{array}{l}\text { Solids and reagent gas feed rates; } \\
\text { vessel temperatures }\end{array}$ & $\begin{array}{l}\text { Solid and gas flowmeters; on-line } \\
\text { temperature meters; }\end{array}$ \\
\hline Product collection & $\begin{array}{l}\text { U concentration in the solids; solids } \\
\text { weight }\end{array}$ & $\begin{array}{l}\text { Periodic process sampling for } \mathrm{U} \\
\text { content; level indication on solids } \\
\text { collector; on-line weigh scales }\end{array}$ \\
\hline \multicolumn{3}{|c|}{ Hydrofluorination/fluorination } \\
\hline Reaction vessel & $\begin{array}{l}\text { Solids and reagent gas feed rates; } \\
\text { vessel temperatures }\end{array}$ & $\begin{array}{l}\text { Solid and gas flowmeters; on-line } \\
\text { temperature meters }\end{array}$ \\
\hline Product collection & $\begin{array}{l}\text { U concentration in the solids; solids } \\
\text { weight }\end{array}$ & $\begin{array}{l}\text { Periodic process sampling for U } \\
\text { content; level indication on solids } \\
\text { collector; on-line weigh scales }\end{array}$ \\
\hline \multicolumn{3}{|c|}{ Reduction } \\
\hline Reaction vessel & Vessel temperatures & $\begin{array}{l}\text { U metal weight; sampling of metal } \\
\text { product for impurities, density, U } \\
\text { content; on-line temperature meters }\end{array}$ \\
\hline
\end{tabular}




\section{CURRENT PROCESS-MONITORING EQUIPMENT USED BY IAEA}

The IAEA currently uses process monitoring techniques in its safeguards approach for various facilities, such as at reprocessing facilities and research reactors. The IAEA is also developing process-monitoring techniques for the process and transfer areas of mixed oxide fuel fabrication and the load cell monitors for gas centrifuge enrichment plants.

At bulk handling facilities the IAEA uses process monitoring with a focus on "off-normal plant operation" to complement its nuclear material accounting safeguards approach. ${ }^{5}$ Process-monitoring measures at reprocessing facilities and other bulk handling facilities include solution monitoring of tanks, specifically their individual masses and volumes (and densities). Measurements may also be made on operator process data such as the temperature gauges and in-line flow monitors (including concentration measurements).

A good example of where process monitoring is used as part of the overall safeguards program is in the measurement and monitoring of fissile solutions at the Tokai Reprocessing Plant (TRP) in Japan. ${ }^{6,7}$ In that facility, the IAEA solution measurement and monitoring system (SMMS) is applied on the chemical liquid processing part of the plant operation that includes dissolution/clarification, extraction, purification and concentration, and the High Active Liquid Waste treatment/storage. SMMS involves more than 90 vessels or other equipment (e.g., evaporators, extractors). The installed measurement instruments provide signals for pressure, temperature, and/or neutron count rates. Two different types of solution-monitoring systems are used in the reprocessing plant:

- SMMS-1 uses highly accurate IAEA-owned differential manometers that are connected directly to the operator's equipment (i.e., pneumatic dip tubes). These instruments are applied on the most strategic vessels in the main process line (e.g., the input/output accountancy tanks), some key vessels between the two extraction cycles and after the second cycle, and all tanks with a highly concentrated plutonium solution. The system also includes PLCs for instrument interface and personal computers for data collection, evaluation of state-of-health information, and data buffering and authenticated data transmission to the inspector's data collection and evaluation (DC\&E) computer.

- $\quad$ SMMS-2 is an operator-owned system that uses mainly industrial pressure measurement devices in 80 process vessels. The instruments used include pressure or temperature sensors as well as neutron detectors mounted on the extractors in the main process. The signal is split from the operator pressure transducers and is sent to the IAEA cabinets in each building and then to the inspector's DC\&E computer.

One key aspect to solution monitoring is the management and evaluation of the large amounts of data that are collected. Solution Monitoring Software (SMS) was developed specifically to process and evaluate data from the SMMS sensors automatically. The SMS can detect events in a series of data, compare the events with reference signatures, and raise alarms in case of differences (autocorrelation). It also calculates the volume transferred at the various flow points and correlates the information between sender and receiver vessels (cross-correlation). It provides the inspector with a high-level graphical user interface for configuration, parameterization, or evaluation. Inspectors can use the data as part of their verification activities to verify inventory, changes to inventory, and flows within the process.

Another example of where the IAEA uses process monitoring is in research reactor safeguards. ${ }^{8}$ In that application, an advanced thermohydraulic power monitor (ATPM) monitors the power output of a research reactor and verifies that the output is consistent with the operator-declared power level. The ATPM monitors the temperature and water flow in the reactor's primary cooling loop by using resistive 
type temperature sensors and ultrasonic flow monitors on the hot and cold sides of the primary core cooling loop. The output from the sensors provides a velocity measurement on the cooling loop's water and the temperature drop as heat is removed from the loop. The collected data are used to calculate the reactor power output. 


\section{NONTRADITIONAL MONITORING METHODS}

Other monitoring methods in addition to the types of process monitoring already discussed may be necessary to adequately verify that material is not being diverted or that undeclared material is not being processed in an NUCF. Determination of uranium content at NUCFs is typically done by periodically taking samples throughout the process and performing destructive analysis. On-line, nondestructive analysis for uranium determination is typically not used in NUCFs. On-line analyses using such methods as refractive index analysis, electrochemical analysis, or off-gas analysis at an NUCF may be viable alternative options for use in safeguards monitoring.

One area where diversion in an NUCF may occur is at solvent extraction. This process involves several extraction streams in which uranium is transitioning between each stream at varying rates. That part of an NUCF probably provides the most challenging process to the IAEA inspectors in regard to determining U flow and processing. Simultaneous real-time monitoring of the uranium concentration in each of the extraction streams (i.e., feed, organic, raffinate) would be very beneficial in determining uranium flow through this complex operation. One method that could be used for monitoring is that of refractive index analysis. Such analyzers use visible near-infrared and Raman spectroscopy to determine specific ion concentrations in extraction solution streams. The ability to identify material intentionally diverted from a liquid-liquid solvent extraction system has been demonstrated effectively. ${ }^{9}$

The waste streams in an NUCF typically contain low concentrations of uranium in nonhomogeneous mixtures, making measurement of the uranium difficult. Thus they hinder the determination of the overall uranium material balance in the NUCF and present opportunities for material diversion. Electrochemical methods such as differential pulse voltammetry (DPV) have been demonstrated for use in the determination of uranium in low-concentration streams generated at an NUCF. Electrochemical methods are well suited for this purpose because they are capable of analyzing trace quantities with reasonable precision and accuracy. ${ }^{10}$ The use of DPV as an in-line analyzer has also been demonstrated by Kuno et al. for the determination of uranium and plutonium in a reprocessing plant. In that study, in-line analytical $\mathrm{U}, \mathrm{Pu}$, and acidity in mainstream solutions at TRP were determined by combining DPV with electric conductivity or ultrasonic wave velocity measurement using noble metal electrode probes. ${ }^{11}$ The use of such analyzers in an NUCF could aid the inspectors with overall determination of material accountancy.

The undeclared processing of uranium in an NUCF is a major concern for safeguards. One possible option for monitoring such activities is the use of in-line analyzers in off-gas streams from the various processes in the NUCF. For instance, nitrous oxides are generated during the dissolution of UOCs, ammonia is generated during conversion of ammonium diuranates or ammonium diuranyl carbonates (AUCs) to oxides, water is generated in the hydrofluorination of $\mathrm{UO}_{2}$ to $\mathrm{UF}_{4}$, and excess hydrogen and hydrogen fluorides are used in oxidation and hydrofluorination processes. In-line analyzers for such gases

are routinely used in various chemical industries, and it is possible that such analyzers could be used in an NUCF although no evidence of evaluations of these types of analyzers for use in NUCFs has been identified.

At an existing NUCF, the use of these nontraditional monitoring methods could be quite an extensive intrusion or a relatively minor intrusion, depending on the available facility space and infrastructure and on the size, design, and integration of the monitoring equipment (i.e., piping, instrumentation, electrical, utilities). Implementation of this type of equipment will require close coordination with the facility operator to ensure that it can be retrofitted into existing plant equipment. Although these methods may not prove to be precise enough for determining overall uranium material balances in an NUCF, they would be good tools to use in the monitoring of processing activities, thus making it more difficult for the operators to perform undeclared processing of uranium. Also, nontraditional monitoring methods can help in 
determining overall material accountancy, which would make overproduction of material more difficult to achieve. 


\section{PROCESS-MONITORING USE FOR AN ENHANCED IAEA APPROACH TO NUCF SAFEGUARDS}

Conventional approaches for safeguarding nuclear materials rely, in large part, on destructive analyses to quantify the amount of nuclear material within bulk handling facilities and to verify the location of all material to within an SQ. Although the accuracies of destructive analyses are superb, they are extremely resource intensive, have limited sampling rates, and are associated with a significant time lag from sampling to final reporting. In addition, the error associated with destructive analyses scales with the size of the facility. ${ }^{12}$ The integration of a variety of on-line process-monitoring tools with these conventional approaches could provide a more robust framework that would use both material accountancy and augmented material control via continuous process flow sheet verification.

Inclusion of process monitoring in safeguards could provide the IAEA inspectors with remote, real-time information of NUCFs, which may allow for optimization of inspections, resulting in reduced on-site visits. By having remote access to near-real-time process information, the inspectors can develop trending of material processing and plant operations, which can be factored into determining optimal times and activities for on-site inspections as well as more detailed input parameters to IAEA for simulation modeling of the uranium conversion material processes. Also, using a combination of process measurements, such as $\mathrm{pH}$, flow rates, temperature and pressure changes, liquid levels, and material weights, can create a signal that is very difficult to spoof by the operator.

A comprehensive process-monitoring plan for an NUCF must account for normal operating modes as well as off-normal modes. Key equipment should be monitored for possible deviation from standard operations. Process monitoring could possibly provide inspectors with the ability to detect changes that could indicate facility misuse and provide continuity of knowledge to support the concept that an NUCF is operating as declared. The use of process monitoring for safeguards would require close coordination between the IAEA and the facility operator.

Process monitoring for safeguards has three key elements: (1) the data and instrumentation involved, (2) the data collection and storage platforms, and (3) the evaluation software. ${ }^{13}$ Establishment of an enhanced IAEA safeguards approach for NUCFs should consider each of these key elements in the integration of process monitoring into an overall safeguards plan.

\subsection{DATA AND INSTRUMENTATION}

Process monitoring at key measurement points (KMPs) in NUCFs should be evaluated and considered for use as part of an overall safeguards plan. A safeguards system that uses a combination of accountability principles with unattended monitoring to verify data would significantly enhance a diversion detection system. R. L. Faulkner et al. have proposed that "the optimum system would include verifiable accountability data for feed and the withdrawal streams" as well as the presence of multiple in-line detection systems. As shown in Fig. 2, the researchers identify eight KMPs in an overall uranium conversion process for possible monitoring or accountability ${ }^{3,14}$ :

- the solid feed entering the plant,

- the solid feed being fed to the dissolver,

- the uranyl nitrate solution before purification,

- the uranyl nitrate strip solution just after purification,

- the stripped organic solvent just after purification,

- the purified uranyl nitrate solution after being concentrated in the evaporator,

- the first solid uranium after purification (after precipitation or thermal denitration),

- the final product. 


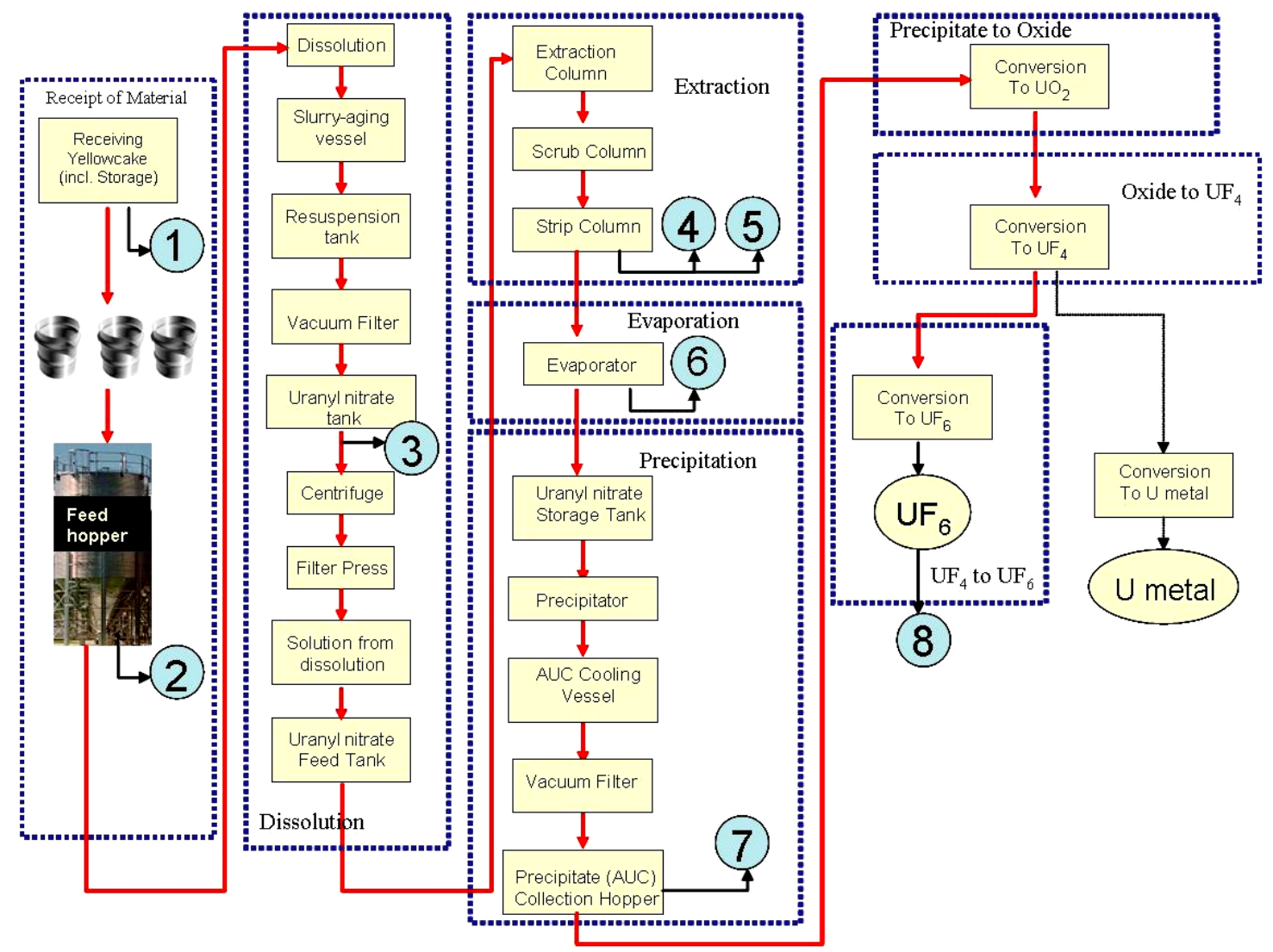

Fig. 2. Recommended key measurement points.

With all eight monitoring points, the probability of detecting a diversion of an SQ of uranium becomes high for small- and medium-size plants. The large plants may have a high detection capability if special attention is placed on waste stream disposition, which may require additional KMPs. Uranium materialincluding all the solid intermediate products and the $\mathrm{UF}_{6}$ product - becomes significantly more attractive for diversion after purification. The overall uranium mass balance is obtained from the uranium entering in the feed and leaving as product (taking into account plant efficiency), equipment holdup, MUF, and waste streams. Undeclared feed could be introduced at any point along the flow path.

The following list addresses the types of monitoring that could be used at each of the KMPs for accountability of material and to detect off-normal operations.

- KMP1:UOC Receipt

- Accountability: Yellowcake feed to NUCF; validation of operator-supplied data regarding UOC receipts, including independent weight of UOC containers and samples for destructive analysis.

- KMP2:UOC Feed to Dissolver

- Accountability: Change in weight of feed hopper using in-line weigh scale if available and feed rate from hopper to dissolver tank in combination with declaration of UOC feed supplied by operator to IAEA and results of destructive analysis samples. 
- Diversion/Additional Processing: Position of feed valve or feed mechanism to dissolver with respect to time and hopper level indication. This information would provide inspectors with changes in contents of UOC feed hopper, which would provide some indication of material flow to the dissolver. Indication of diversion of material could be determined by comparing this actual data to the operator-declared feed.

- KMP3: Impure Uranyl Nitrate Storage

- Accountability: Difficult to determine uranium content at this point, given impurities and the fluctuating uranium concentrations due to varying UOC feeds to the dissolver. The only option would be for some type of on-line uranium analyzer or possibly a refractive index analyzer that to date has not been used in conversion facilities.

- Diversion/Additional Processing: Position of feed valve and outlet valve on uranyl nitrate storage tank and tank level indication with respect to time. This information would provide inspectors with information on material movement of the impure uranyl nitrate between processes. Also monitoring of solution density and $\mathrm{pH}$ may provide indication of substitution of materials (i.e., diversion) although these parameters will change throughout the process somewhat depending upon the variability of the UOC feed to the dissolver.

- KMP4,5: Purified Uranyl Nitrate and Organic Streams from Extraction

- Accountability: Determine changes in uranium concentration and in these streams using refractive index analysis and transfer of material using in-line flowmeters. It is also possible to determine uranium concentration in the aqueous product stream by measuring solution density, $\mathrm{pH}$ and conductivity. ${ }^{15}$

- Diversion/Additional Processing: In-line flow monitoring of organic and aqueous streams leaving extraction columns; in-line monitoring of free acid content of organic stream.

- KMP6: Purified and Concentrated Uranyl Nitrate

- Accountability: Determine uranium concentration by measuring solution density, $\mathrm{pH}$, and conductivity coupled with in-line flow measurements downstream of evaporator product.

- Diversion/Additional Processing: In-line flow measurement in product stream immediately upon leaving evaporator combined with level indication of downstream uranyl nitrate storage tank.

- KMP7-Precipitate Product

- Accountability: Change in weight of collection hopper using in-line weigh scale if available and results of periodic destructive analysis samples of precipitate would provide estimate of U.

- Diversion/Additional Processing: Position of feed valve and outlet valve on precipitate storage hopper and hopper weight with respect to time.

- $\mathrm{KMP} 8-\mathrm{UF}_{6}$ Product

- Accountability: Weight of $\mathrm{UF}_{6}$ cylinders and samples of $\mathrm{UF}_{6}$ for destructive analysis.

- Diversion/Additional Processing: Position of outlet valves from $\mathrm{UF}_{6}$ desublimers combined with on-line measurements of $\mathrm{UF}_{6}$ cylinder weights. 
Table 2 includes a summary of the types of process monitoring at various measuring points in an NUCF that would enhance the ability of the safeguards inspectors to verify and validate material processing and accountability.

Table 2. Safeguards process monitoring for the suggested monitoring points at NUCF

\begin{tabular}{|c|c|c|}
\hline $\begin{array}{c}\text { Monitoring } \\
\text { point number }\end{array}$ & Process parameters & Process monitoring \\
\hline 1 & $\begin{array}{l}\text { Solid yellowcake is received in drums, } \\
\text { stored, and dumped into feed hopper for } \\
\text { dissolver }\end{array}$ & $\begin{array}{l}\text { Accounting with grab samples taken for } \\
\text { destructive analysis; facility declaration to } \\
\text { IAEA }\end{array}$ \\
\hline 2 & $\begin{array}{l}\text { Solid yellowcake fed from bottom of feed } \\
\text { hopper to the dissolver }\end{array}$ & $\begin{array}{l}\text { Feed rate of solids from hopper to dissolver } \\
\text { (infer from rotational speed of solids feed } \\
\text { mechanism); weight change in hopper (if on- } \\
\text { line scale used); feed valve position between } \\
\text { hopper and dissolver in conjunction with } \\
\text { dissolver solution temperatures. }\end{array}$ \\
\hline 3 & Unpurified uranyl nitrate solution & $\begin{array}{l}\text { In-line monitoring of } \mathrm{pH} \text {, density, } \\
\text { conductivity, liquid level changes and } \\
\text { inlet/outlet valve positions dissolver product } \\
\text { storage tank }\end{array}$ \\
\hline 4 & Purified uranyl nitrate solution & $\begin{array}{l}\text { In-line monitoring of } \mathrm{pH} \text {, density, } \\
\text { conductivity, liquid level changes and } \\
\text { inlet/outlet valve positions purified uranyl } \\
\text { nitrate product storage tank }\end{array}$ \\
\hline 5 & Stripped organic liquid & In-line monitoring of free-acid content. \\
\hline 6 & $\begin{array}{l}\text { Concentrated purified uranyl nitrate } \\
\text { solution }\end{array}$ & $\begin{array}{l}\text { In-line monitoring of density, liquid level } \\
\text { changes and inlet/outlet valve positions in } \\
\text { uranyl nitrate product storage tank }\end{array}$ \\
\hline 7 & Purified solid dry uranium $\left(\mathrm{AUC}\right.$ or $\left.\mathrm{UO}_{3}\right)$ & $\begin{array}{l}\text { Accounting with grab samples taken for } \\
\text { destructive analysis and rate of solids } \\
\text { discharged from process to collection (infer } \\
\text { from rotational speed of solids transfer } \\
\text { mechanism); weight change in product } \\
\text { collection (if on-line scale used) }\end{array}$ \\
\hline 8 & $\mathrm{UF}_{6}$ collected and stored in cylinders & $\begin{array}{l}\text { Accounting with grab samples taken for } \\
\text { destructive analysis and weight change in } \\
\text { product collection (if on-line scale used) }\end{array}$ \\
\hline
\end{tabular}

\subsection{DATA COLLECTION AND STORAGE PLATFORMS}

Most industries, including NUCFs, use DCSs for operator interface to plant operations, accessibility to plant data, and historical storage and retrieval systems (i.e., data trending). A DCS is typically a hardwired system and exists within finite boundaries, such as a process plant or a factory. DCSs differ in terms of complexity and applications. Smaller implementations may consist of a single PLC connected to a computer in a remote office. Larger, more complex DCS installations are also PLC-based, but special enclosures are used for subsystems that provide both input/output and communication. Wireless systems are starting to become popular and hold the promise of improved flexibility in both physical and logical layout of the facility. 
True DCSs use localized control, which is in turn controlled by the operator located at a central location. DCSs consist of the following:

- remote control panels;

- a communications medium;

- a central control panel or facility; and

- control, interface, and database software.

IAEA access to plant data would not require redundant process-monitoring equipment but would require secure remote access to the same data that are available to the plant operators for specific measurements (i.e., access to the communications medium from individual remote-control panels). This access to plant data will require significant negotiations between the NUCF operator and the IAEA. The challenge in setting up this type of access depends on what the NUCF owner considers to be proprietary. The amount of data collected will depend, in large part, on the throughput and operational modes (i.e., batch, continuous) of the NUCF. Ways to condense or minimize the amount of data collected could include the use of trending and/or value averaging (i.e., average solution flow rates per shift) or taking periodic data snapshots of operations. Process-monitoring data should include all aspects of plant operation, including start-up, steady state, off-normal, and standby conditions.

One issue that must be addressed before process monitoring can be used as part of safeguards is authentication of the data. The IAEA must be assured that any safeguards collected process data are authentic (i.e., have not been altered after they were taken). The authentication process should include measures to ensure the authenticity of the hardware, the data collection environment, data transmission, and protection of secret and private keys used for cryptographically signing the data.

One example where the issue of authentication has been addressed is in a joint collaboration effort between the US Department of Energy and the European Safeguards Research and Development Association. ${ }^{16}$ As part of that collaboration, a system, referred to as the Enhanced Data Authentication System (EDAS), was developed. EDAS was designed to provide the ability to transparently capture, authenticate, and encrypt communication data that are transmitted between operator control computers and connected process equipment/sensors. The authenticated and encrypted data are then sent to IAEA data collection equipment. EDAS was configured to capture information as close to a sensor point as possible to ensure the highest possible confidence in the collected data. It employs public key authentication providing "jointly verifiable" data and private key encryption for confidentiality as well as the inclusion of time stamps and data source as part of the collected data. EDAS is a good example of the type of equipment that would be necessary to interface between the IAEA data collection systems and the plant process-measuring sensors and equipment. This type of system, while transparent to the plant operations, can provide the necessary assurance to the IAEA that the collected and transmitted data have not been tampered with.

\subsection{EVALUATION SOFTWARE}

Evaluation of the various process data collected from an NUCF will require at least some modeling of process operations. Process simulation in industrial plant design and operation is one way to provide inspectors with an idea of what should be happening in an NUCF, given specific feed and a description of relevant simulation codes currently used by industry. Simulation codes in tandem with advanced monitoring can play a significant role in the development and implementation of improved safeguards tools. Another method for evaluating process data is to establish snapshots of operations for a specific period of time for vessels and equipment and then to develop sequential analysis of a series of these snapshots for a basis of the process-monitoring evaluation. This method has been demonstrated in data collection systems used during diversion detection tests conducted for safeguards purposes at Barnwell, 
South Carolina and at Oak Ridge National Laboratory, Oak Ridge, Tennessee. ${ }^{17}$ In the tests, algorithms were developed to interpret changes between the snapshots, and evaluation software was used to assess the changes and to recognize them as expected or to alarm them as possible concerns. Specific algorithms were developed that took into consideration the operating characteristics of each piece of equipment and related process systems. Data collection and evaluation systems would require customization for each NUCF. A good example of such customization is the SMS deployed at TRP. 


\section{COST AND RELIABILITY CONSIDERATIONS}

Integrating process monitoring into safeguards monitoring depends upon the types of instrumentation and control systems that exist in the NUCF. Retrofitting process monitoring into an NUCF would be costly and would likely require significant engineering to accomplish, depending upon the extent to which process monitoring is used. It would likely be more economical to include process monitoring in Safeguards by Design for new NUCFs than to retrofit. ${ }^{18}$

It is difficult to estimate costs, given the variety of process-monitoring approaches and, more importantly, the various types of technology and the level of automation. One significant cost for existing facilities would be developing, designing, and installing data collection equipment that can interface between process sensors/equipment/data systems and IAEA data collection/transmission equipment. Depending upon the design, the equipment could involve a significant plant infrastructural interface (i.e., cabling to/from sensors/equipment and IAEA systems, electrical, ventilation for instrument cabinets). Another cost would be in the evaluation of implementation of such a system to the overall process safety. Tie-ins to existing sensors and equipment would have to be evaluated to ensure that plant operations and safety are not adversely affected.

Measuring the effectiveness of process monitoring is an ongoing discussion in the international safeguards community and at the IAEA. It was identified in 2011 as one of the "technical challenges" facing the IAEA. ${ }^{19}$ Process monitoring can be customized to specific potential diversion pathways at NUCFs, making it very effective against specific safeguards objectives (especially when implemented in combination with nuclear material accounting and surveillance and containment methods). Process monitoring can also provide the inspectors with a better understanding of operational time lines (i.e., processing time vs. downtime, time required for start-up and shutdown vs steady-state conditions), which can be factored into optimizing the timing and activities of on-site inspection. By having a better understanding of how the processes are operated, the inspectors can efficiently plan their visits to maximize what they can see in a short time span and possibly schedule fewer annual visits to a facility. 



\section{CONCLUSIONS}

The integration of process monitoring in a plant's overall safeguards program could significantly aid the IAEA inspectors in their verification of state declarations or in identification of possible diversions of material. The safeguards systems that have been developed and installed at reprocessing facilities in Japan have demonstrated that process monitoring can be used in processes similar to what one would find in NUCFs (i.e., dissolution, extraction, solution management). Incorporating process monitoring into an NUCF's safeguards plan is technically feasible and can provide a much better understanding of plant operations both in normal and off-normal modes. The challenge will be the willingness of the operator to allow inspector access to the types of operational information process monitoring can provide and the ability to ensure that collected data are authentic and have not been tampered with prior to transmission to the IAEA.

One area that should be considered for further evaluation is to determine how signals to and from process instrumentation can be branched so that the IAEA inspectors would have access without causing any impacts to operations. Also, demonstration of the authenticity of the data is necessary to verify for the IAEA that the data accurately reflect material processing and have not been altered. This area of study is crucial in the ability to use process monitoring as part of an NUCF's overall safeguards program. 



\section{REFERENCES}

${ }^{1}$ IAEA, Safeguards Approaches for Natural Uranium Conversion Plants, Safeguards Technical Report 342 (STR 342), International Atomic Energy Agency, Vienna, February 2004.

${ }^{2}$ IAEA, Safeguards Measures Applicable in Conversion Plants Processing Natural Uranium, Safeguards Policy Series, Number 18, International Atomic Energy Agency, Vienna, June 2003.

${ }^{3}$ R. Faulkner et al., "Oak Ridge Efforts to Enhance Conversion Plant Safeguards," presented at the INMM 45th Annual Meeting, Orlando, Florida, 2004.

${ }^{4}$ J. M. Schisler, "Commissioning and Startup of the Blind River Uranium Refinery," Minerals and Metallurgical Processing, 15-19, (February 1986).

${ }^{5}$ T. Burr et al., "Roles for Process Monitoring in Nuclear Safeguards at Aqueous Reprocessing Plants," Journal of Nuclear Materials Management 40 (2), 42-53 (2012).

${ }^{6}$ M. H. Ehinger, Lessons Learned in International Safeguards-Implementation of Safeguards at the Rokkasho Reprocessing Plant, ORNL/TM-2010/23, Oak Ridge National Laboratory, Oak Ridge, Tennessee, December 2009.

${ }^{7}$ C. V. Handenhove et al., Development of Solution Monitoring Software for Enhanced Safeguards at a Large Scale Reprocessing Facility, ESARDA Bulletin No. 46, December 2011.

${ }^{8}$ IAEA, Safeguards Techniques and Equipment: 2011 Edition, International Nuclear Verification Series No. 1 (Rev. 2), International Atomic Energy Agency, Vienna, 2011.

${ }^{9}$ C. R. Orton et al., FY-2010 Process Monitoring Technology Final Report, PNNL-20022, Pacific Northwest National Laboratory, Richland, Washington, January 2011.

${ }^{10}$ L. R. Sawant et al., "Differential Pulse Voltammetric Determination of Uranium in Low Concentration Streams," Journal of Radioanalytical and Nuclear Chemistry 207 (1), 39-43 (1996).

${ }^{11}$ T. Kuno et al., In-Line Determination of Uranium, Plutonium and Acidity in Spent Fuel Reprocessing for Process Monitoring on Advanced Nuclear Material Verification, IAEA-CN-184/55, International Atomic Energy Agency, Vienna, October 2010.

${ }^{12}$ C. R. Orton et al., FY-2010 Process Monitoring Technology Final Report, PNNL-20022, January 2011.

${ }^{13}$ M. Ehinger et al., Process Monitoring for Safeguards: FY2008 Task Summaries, ORNL/TM-2009/097, Oak Ridge National Laboratory, Oak Ridge, Tennessee, March 2009.

${ }^{14}$ B. Boyer et al., Systems Modeling Framework for Assessing Safeguards Approaches for a Generic Natural Uranium Conversion Plant (NUCF), BNL 077317-2006, Brookhaven National Laboratory, Upton, N.Y., August 15, 2006.

${ }^{15}$ J. L. Bolts, R. J. Raridon, and D. A. Costanzo, Density, Acidity, and Conductivity Measurements of Uranyl Nitrate/Nitric Acid Solutions, ORNL/TM-6491, Oak Ridge National Laboratory, Oak Ridge, Tennessee, October 1978.

${ }^{16}$ T. Ross et al., Verifiable Process Monitoring Through Enhanced Data Authentication, IAEA-CN184/118, International Atomic Energy Agency, Vienna.

${ }^{17}$ M. Ehinger, et al., Process Monitoring for Safeguards: FY2008 Task Summaries, ORNL/TM-2009/097, Oak Ridge National Laboratory, Oak Ridge, Tennessee, March 2009.

${ }^{18}$ L. Loden and J. Begovich, Implementing Safeguards-by-Design at Natural Uranium Conversion Plants, NGSI-SBD-002, Safeguards-By-Design Facility Guidance Series. NNSA, 2012. Available at http://www.nnsa.energy.gov/safeguardsbydesign.

${ }^{19}$ T. Burr et al., "Strengthened Nuclear Safeguards: A Statistical View in the Context of Combining Process Monitoring and Nuclear Material Accounting Data," Journal of Nuclear Materials Management 40 (4), 115-129 (2012). 
